\title{
Rickettsia rickettsii growth and temperature- inducible protein expression in embryonic tick cell lines
}

\author{
PAUL F. POLICASTRO, ULRIKE G. MUNDERLOH*, ELIZABETH R. FISCHER $\dagger$ and TED HACKSTADT \\ Laboratory of Intracellular Parasites and †Microscopy Branch, Rocky Mountain Laboratories, NIAID, NIH, \\ Hamilton, Montana 59840 and *Department of Entomology, University of Minnesota, St Paul, Minnesota \\ 55180, USA
}

\begin{abstract}
Rickettsia rickettsii has limited adverse effects on its arthropod vector, but causes severe disease in man. To model differences in host-parasite interaction, $R$. rickettsii growth and protein expression were examined at temperatures reflective of host environment in the tick cell lines DALBE3 and IDE2, the human endothelial cell line ECV304, and the African green monkey kidney cell line Vero76. At low multiplicities of infection, rickettsial titres increased $10^{2}-10^{3}$-fold in all cell lines after incubation for 3 days at $34^{\circ} \mathrm{C}$. At higher multiplicites and with extended incubation, $R$. rickettsii showed enhanced survival in tick versus mammalian cells. No difference in rickettsial ultrastructure or protein profiles was detected between different host cell types. Rickettsial proteins of 42, 43, 48, 75 and $100 \mathrm{kDa}$ are induced in tick cells shifted from $28^{\circ}$ to $34^{\circ} \mathrm{C}$, but not in cells maintained at $28^{\circ} \mathrm{C}$. This temperature response may be associated with expression of rickettsial determinants that are pathogenic to mammalian hosts.
\end{abstract}

\section{Introduction}

Many spotted fever group rickettsiae, including Rickettsia rickettsii, $R$. conorii, $R$. siberica, $R$. akari and $R$. japonica, cause severe disease in man, but maintain long-term, essentially commensal relationships with their tick or mite hosts $[1,2]$. This disparity in the interaction of rickettsiae with mammalian and arthropod hosts presumably reflects host-adaptive patterns of bacterial gene expression. Rickettsiae are obligate intracellular bacteria that can be propagated in embryonated eggs, chick embryo fibroblasts and various mammalian cell types $[3,4]$. Rickettsiae propagated by these methods have been used to identify antigens eliciting strong humoral immune responses [5-9].

Various environmental signals have been shown to influence patterns of gene expression in bacterial pathogens $[10,11]$. A recent example of inducible expression in a tick-borne bacterial pathogen is the OspC outer surface protein of Borrelia burgdorferi, which is expressed upon blood feeding by infected ticks or upon a temperature shift from $24^{\circ} \mathrm{C}$ to $32^{\circ}-$ $37^{\circ} \mathrm{C}$ in vitro [12]. A temperature increase from $20^{\circ} \mathrm{C}$ to $37^{\circ} \mathrm{C}$ of the infected tick host Dermacentor

Received 4 Feb, 1997; accepted 25 March 1997. Corresponding author: Dr P. F. Policastro. andersoni has long been implicated in enhanced infectivity of $R$. rickettsii $[12,14]$.

In considering potential roles of rickettsial proteins in human vascular disease, the study aimed to investigate whether certain proteins are constitutively expressed or are induced by host or environmental conditions. The arthropod-vertebrate host transition represents a key change in rickettsial environment, providing signals that may result in adaptive patterns of bacterial gene expression. This study examined the growth of $R$. rickettsii in tick and mammalian cell lines and analysed the effect of temperature on rickettsial protein expression in tick cells.

\section{Materials and methods}

Cell lines and growth of $R$. rickettsii in cell culture

Vero76 African green monkey kidney fibroblast cell line (ATCC CRL 1587) and ECV304 human umbilical vein endothelial cell line (ATCC CRL 1998) were maintained in culture as recommended (American Type Culture Collection, Rockville, MD, USA). The IDE2 cell line is an embryonic tick cell line obtained from Ixodes scapularis eggs [15]. DALBE3 was derived from Dermacentor albipictus eggs essentially as 
described for the Ixodes cell line. Both lines were maintained in L15B medium [16] containing Tryptose Phosphate Broth (TPB; Difco) 10\%, heat-inactivated fetal calf serum (FCS; Life Technologies, Gaithersburg, MD, USA) $5 \%$, bovine cholesterol concentrate (ICN, Irvine, CA, USA) $10 \mu \mathrm{g} / \mathrm{ml}$ penicillin (Sigma) 50 units $/ \mathrm{ml}$ and streptomycin (Sigma) $50 \mu \mathrm{g} / \mathrm{ml}$. IDE2 was grown at $30^{\circ} \mathrm{C}$ and DALBE3 was grown at $34^{\circ} \mathrm{C}$. $R$. rickettsii $\mathrm{R}$ strain, with a cumulative history of 53 yolk sac passages, one chicken embryo fibroblast passage (plaque isolate), four yolk sac passages, and two Vero76 passages (plaque isolate), was used as inoculum within four subsequent Vero76 passages. Inoculum titres were determined as described previously [17]. Cells to be infected were trypsinised (Vero76 and ECV304) or dislodged by repeated pipetting (IDE2 and DALBE3), counted and plated in antibiotic-free medium at $2.5 \times 10^{5} / \mathrm{ml}, 6 \mathrm{ml} / 25-\mathrm{cm}^{2}$ culture flask for determining the time course infection. Twenty-four h after plating, medium was removed, rickettsial inoculum was added in $1 \mathrm{ml}$ of incubation medium and flasks were rocked for $30 \mathrm{~min}$ at room temperature before the addition of M199 (Life Technologies) containing $\mathrm{NaHCO}_{3} 0.88 \mathrm{gL}$ and heatinactivated FCS29 to Vero76 and ECV3034 cells, or L15B as described above, minus antibiotics, to IDE2 and DALBE3 cells. Flasks were sealed and incubated at the temperature specified in each experiment. At each time-point for rickettsial titre determination, cells were scraped into supernatant medium and sonicated before storage of aliquots at $-70^{\circ} \mathrm{C}$.

\section{Immunoblot analysis of rickettsial antigens}

Total lysates. Thawed aliquots of sonicated material from growth curve analyses were centrifuged for $5 \mathrm{~min}$ at $12000 \mathrm{~g}$, solubilised in RIP buffer - $0.1 \mathrm{M}$ Tris, $\mathrm{pH}$ $8 ; 0.3 \mathrm{M} \mathrm{NaCl} ; 20 \mathrm{mM}$ EDTA; sodium deoxycholate (Sigma) 1\%; Triton X-100 (Sigma) 1\%; SDS (BDH, Poole) $0.2 \%$; $1 \mathrm{mM}$ PMSF (Sigma); pepstatin A (Fluka, Ronkonkoma, NY, USA) $1 \mu \mathrm{g} / \mathrm{ml}$ - mixed with an equal volume of SDS-PAGE sample buffer and boiled for $5 \mathrm{~min}$.

Partially purified lysates. Rickettsiae were partially purified from thawed $1-\mathrm{ml}$ aliquots by centrifugation for $15 \mathrm{~min}$ at $12000 \mathrm{~g}, 4^{\circ} \mathrm{C}$ through $0.5 \mathrm{ml}$ of Renografin (Squibb, Princeton, NJ, USA) $30 \%$ in BHI prior to solubilisation and boiling as above. Samples were separated by SDS-PAGE in 10\% gels [18]. Antigens were transferred to immobilon-P (Millipore, Bedford, MA, USA) as described previously [19], modified by use of $25 \mathrm{~mm}$ sodium phosphate, $\mathrm{pH} 7.4$, for transfer buffer at $32 \mathrm{~V}$ (1.0 amps) for $2.5 \mathrm{~h}$. Filters were incubated with hyperimmune rabbit antiserum to formalin-fixed $R$. rickettsii Shelia Smith strain, washed and incubated with ${ }^{125}$ I-labelled protein A (DuPont NEN, Boston, MA, USA), each at 1 in 1000 dilution. Antigens were detected by autoradiography (Xomat AR, Eastman Kodak, Rochester, NY, USA).

\section{Electron microscopy of infected cells}

Vero76 and ECV304 cells were trypsinised and DALBE3 and IDE2 were suspended by pipetting from culture flasks, resuspended in complete medium, centrifuged at $600 \mathrm{~g}$ and washed at $4^{\circ} \mathrm{C}$ in $0.1 \mathrm{M}$ sodium cacodylate buffer, $\mathrm{pH} 7.4$, containing $0.1 \mathrm{M}$ sucrose (mammalian cells) or $0.2 \mathrm{M}$ sucrose (tick cells). Cells were fixed for $2 \mathrm{~h}$ in paraformaldehyde $4 \%$ : glutaraldehyde $2.5 \%$ in $0.1 \mathrm{M}$ sodium cacodylate buffer containing $0.2 \mathrm{M}$ sucrose. Cells were post-fixed in Karnovsky's $\mathrm{OsO}_{4} \quad 0.5 \%: \mathrm{K}_{3} \mathrm{Fe}(\mathrm{Cn})_{6} \quad 0.8 \%$ followed by tannic acid $1 \%$, and stained overnight en bloc in uranyl acetate $1 \%$. Samples were dehydrated in a graded ethanol series followed by a transition step with propylene oxide, and embedded in epon-araldite. Thin sections were cut with an RMC MT-7000 ultramicrotome, stained with uranyl acetate $1 \%$ and Reynold's lead citrate and observed at $80 \mathrm{kV}$ on a Philips CM-10 transmission electron microscope.

\section{Results}

\section{Growth and survival of $R$. rickettsii in mammalian and tick cell lines}

To determine their relative ability to support rickettsial growth, $R$. rickettsii were inoculated in Vero 76, ECV304, DALBE3 and IDE2 cells and incubated at $34^{\circ} \mathrm{C}$. Cell sonicates were prepared at various times post-infection (p.i.) and assayed for plaque-forming units (PFU) on Vero76 cells. At low mutiplicity of infection (m.o.i.), all cell lines suported $10^{2}-10^{3}$-fold increases in rickettsial titre over the first $72 \mathrm{~h}$ of incubation (Fig. 1a). The Vero76 cells showed plaque formation at 5 days p.i., without any apparent plaque formation in parallel infections of IDE2 cells.

An intermediate m.o.i., Vero76 and IDE2 cells were compared (Fig. 1b). Vero76 and IDE2 both allowed a $10^{2}$-fold increase in $R$. rickettsii titre, which was sustained in the IDE2 tick cell cultures up to 9 days p.i. However, in Vero 76 cells there was a decline in rickettsial titre to a value less than the input by 7 days p.i. At this m.o.i., IDE2 cells reproducibly showed at least $10^{3}$-fold higher rickettsial titres than Vero 76 cells beyond 7 days p.i. (data not shown).

At high m.o.i. (Fig. 1c), there was no net increase in titre in any of the cell lines by 7 days p.i. Vero76 and ECV304 cells showed a pronounced loss in viable rickettsial titre between 4 and 10 days p.i. IDE2 and DALBE3 cells sustained 10-fold higher titres to 10 days p.i., indicating that $R$. rickettsii remains viable for longer periods in tick cell cultures than in mammalian cell cultures. Microscope examination of cultures at this m.o.i. revealed $>50 \%$ lysis and rounding of Vero 76 and ECV304 cells by 3 days p.i., with accumulation of cell debris and free rickettsiae. IDE2 and DALBE3 cells examined at this time were hyperchromatic and detached from the flask, but without signs of extensive lysis. 

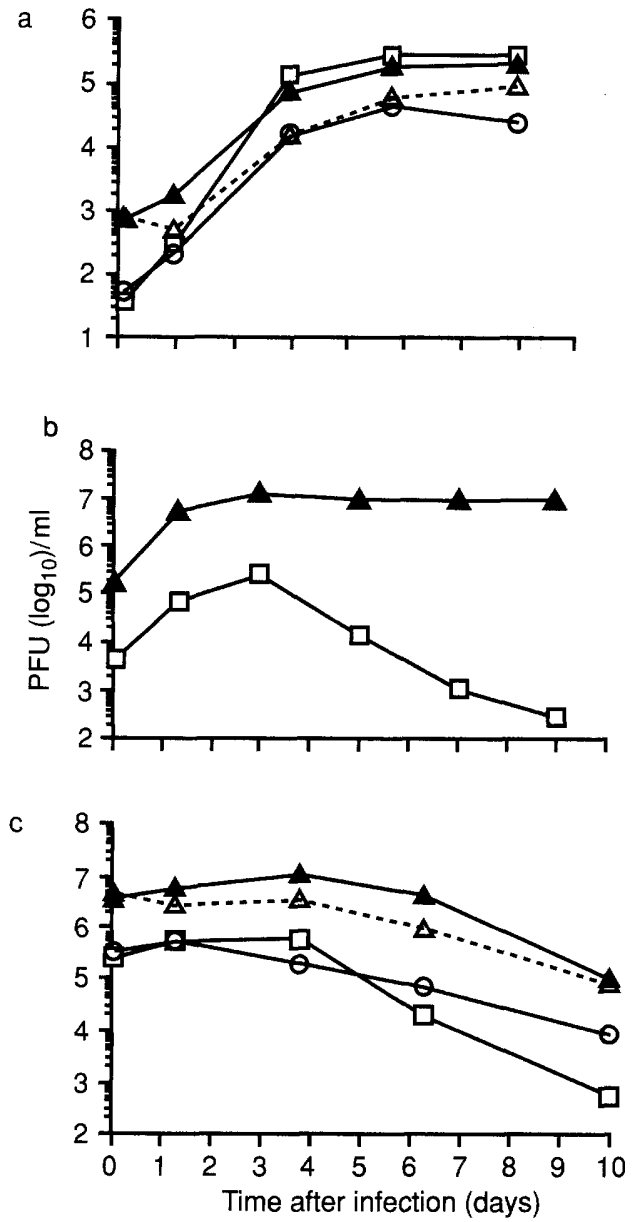

Fig. 1. Growth comparison of $R$. rickettsii in tick and mammalian cell lines. Vero76 (- --$)$ and ECV304 $\left.(-)^{-}\right)$cells were incubated post-infection in M199 medium containing FCS $2 \%$. Tick cell lines DALBE3 $\left(-A^{-}\right)$and IDE2 (-A-) were incubated in L15B. $R$. rickettsii inocula (input PFU) were: (a) $1.5 \times 10^{3}$ (m.o.i. 0.01 ); (b) $1.0 \times 10^{5}$ (m.o.i. 0.2 ); (c) $8.3 \times 10^{5}$ (m.o.i. 5.0). PFU, plaque-forming units; days p.i., time postinfection at which cells were harvested.

\section{Intracellular localisation and morphology or R. rickettsii}

Because the apparent survival rate of $R$. rickettsii in Vero76 and ECV304 cells was less than in IDE2 and DALBE3 cells, the study investigated whether intracellular environments might induce structural or morphological differences that correlate with a lytic or non-lytic host-parasite interaction. Infected cells were fixed at 2 days p.i. and prepared for transmission electron microscopy. Fig. $2 \mathrm{a}-\mathrm{d}$ shows that $R$. rickettsii was found free in the cytosol in all four cell lines, displaying a characteristic electron-lucent zone [20], separating the rickettsial outer membrane from direct contact with the cytoplasm. Vacuoles containing masses of concentric membrane material were common in both infected and uninfected DALBE3 cells (Fig. 2c). Rickettsiae were observed inside vacuoles only rarely in DALBE3 cells. No differences were detected in the ultrastructure of $R$. rickettsii in the varous cell lines with this approach.

\section{$R$. rickettsii antigens in total infected cell lysates}

Rickettsial antigen expression in infected tick and mammalian cell cultures was also examined for any correlation to host-specific survival of $R$. rickettsii. Samples of infected cell lysates from 1, 3 and 7 days p.i. were separated by SDS-PAGE and immunoblots were prepared with rabbit antiserum to formalin-fixed $R$. rickettsii (Fig. 3). In all cell types, rickettsial antigens with apparent $\mathrm{M}_{\mathrm{r}}$ values expected of rOmpA $(190 \mathrm{kDa})$ and $\mathrm{rOmpB} \alpha(135 \mathrm{kDa})$ [21] were detected, in addition to unidentified antigens of $42,43,48$ and $100 \mathrm{kDa}$. The rOmpA and $\mathrm{rOmpB} \alpha$ antigens and the unidentified antigens increased as a proportion of total protein during the time course of the infection.

\section{Temperature dependence of rickettsial protein expression}

As tick species are poikilothermic and experience ambient temperatures lower than the $34^{\circ} \mathrm{C}$ optimum [22] for $R$. rickettsii growth in mammalian cells, the study investigated whether infected DALBE3 cells maintained at $28^{\circ} \mathrm{C}$ display rickettsial protein antigen profiles similar to those in cell maintained at $34^{\circ} \mathrm{C}$. Infected cells incubated at $34^{\circ} \mathrm{C}$ for 1 day p.i. were shifted to $28^{\circ} \mathrm{C}$ for 5 days and then either returned to $34^{\circ} \mathrm{C}$ or maintained at $28^{\circ} \mathrm{C}$ for an additional 5 days. Rickettsiae were partially purified from cell sonicates by centrifugation through Renografin $30 \%$ pads, separated by SDS-PAGE and immunoblotted with anti- $R$. rickettsii serum (Fig. 4). Solubilised samples were loaded so that $\mathrm{rOmpB} \alpha$ acted as an internal standard that was represented at approximately equal intensity in the $28^{\circ}$ and $34^{\circ} \mathrm{C}$ lanes. Antigens of 42,43 , 48,75 and $100 \mathrm{kDa}$ were expressed at $34^{\circ} \mathrm{C}$ but not at $28^{\circ} \mathrm{C}$. A similar pattern of temperature-dependent expression was observed in IDE2 cells infected with $R$. rickettsii (data not shown). The 42-, 43-, 48- and $100-\mathrm{kDa}$ antigens appear to correspond to antigens with these mobilities in total cell lysates identified in the time course infections at $34^{\circ} \mathrm{C}$ (Fig. 3). The $75-\mathrm{kDa}$ antigen also appeared to be detectable in the most heavily infected cell lysates, exemplified by the Vero 76 cells at 7 days p.i.

\section{Discussion}

To understand the basis of the changes in host-parasite interaction that occur upon $R$. rickettsii transmission from a tick vector to a mammalian host, this study compared the growth and protein expression of $R$. rickettsii at temperatures appropriate to the mammalian and tick cell hosts. It was found that the IDE2 and DALBE3 embryonic tick cell lines and the ECV304 human umbilical vein endothelial cell line allowed levels of $R$. rickettsii multiplication at $34^{\circ} \mathrm{C}$ similar to those seen in Vero76 cells. Primary cultures of human umbilical vein endothelial cells are known to support growth and plaque development by $R$. rickettsii, as a 

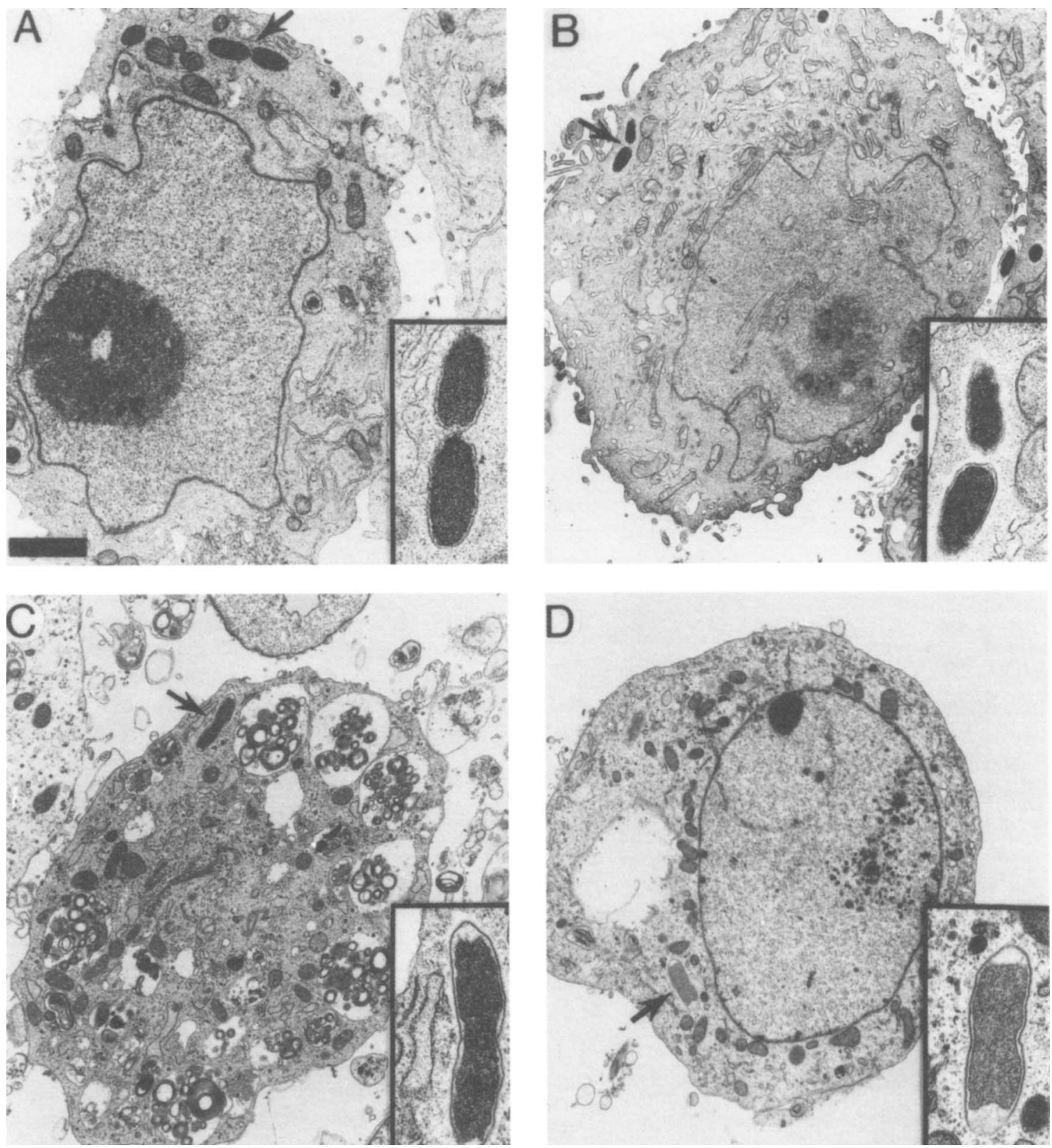

Fig. 2. Intracellular localisation of $R$. rickettsii. Cells infected at m.o.i. 5.0 were fixed at $48 \mathrm{~h}$ p.i. and prepared for transmission electron microscopy. A, Vero76; B, ECV304; C, DALBE3; D, IDE2. Sections were chosen that allowed longitudinal comparison of $R$. rickettsii, Insert in each panel: $3 \times$ enlargement of rickettsial particle indicated by arrow in main panel. All cells shown at same magnification: bar, $2 \mu \mathrm{m}$.

model of cytopathic effects on the vascular endothelium [23-25]. In the present study, the ECV304 line provided a human target cell comparison for tick cell infection by $R$. rickettsii. Certain tick cell lines have been reported to allow rickettsial growth [26, 27], but these reports did not provide details of the infection time course, analyse rickettsial protein expression, or describe the impact of infection on host cell survival. The tick cells in the present study were found to differ from the mammalian cell lines in their ability to sustain rickettsial viability for extended periods of incubation at $34^{\circ} \mathrm{C}$. While mammalian cell monolayers were destroyed and released rickettsial particles, tick cells tolerated the rickettsial burden and showed reduced lysis. There was no obvious difference in rickettsial antigen and protein expression that correlated with this contrast in bacteria-host interaction. Electron microscopy of infected cells showed that $R$. rickettsii was indeed present free within the cytosol of each cell type. We suspect that the tick cells do not provide the opportunity for rickettsial escape and host cell damage that is provided by the mammalian endothelial and fibroblast cells. The mechanism of escape in Vero76 cells, and probably in ECV304 cells, involves actinbased motility [28]. Whether this rickettsial motility mechanism is functional in these tick cell lines or intact tick hosts remains to be tested. Escape from the tick host cell is clearly necessary in the natural transmission cycle that allows passage of $R$. rickettsii from tick gut to other organs, and escape from tick 


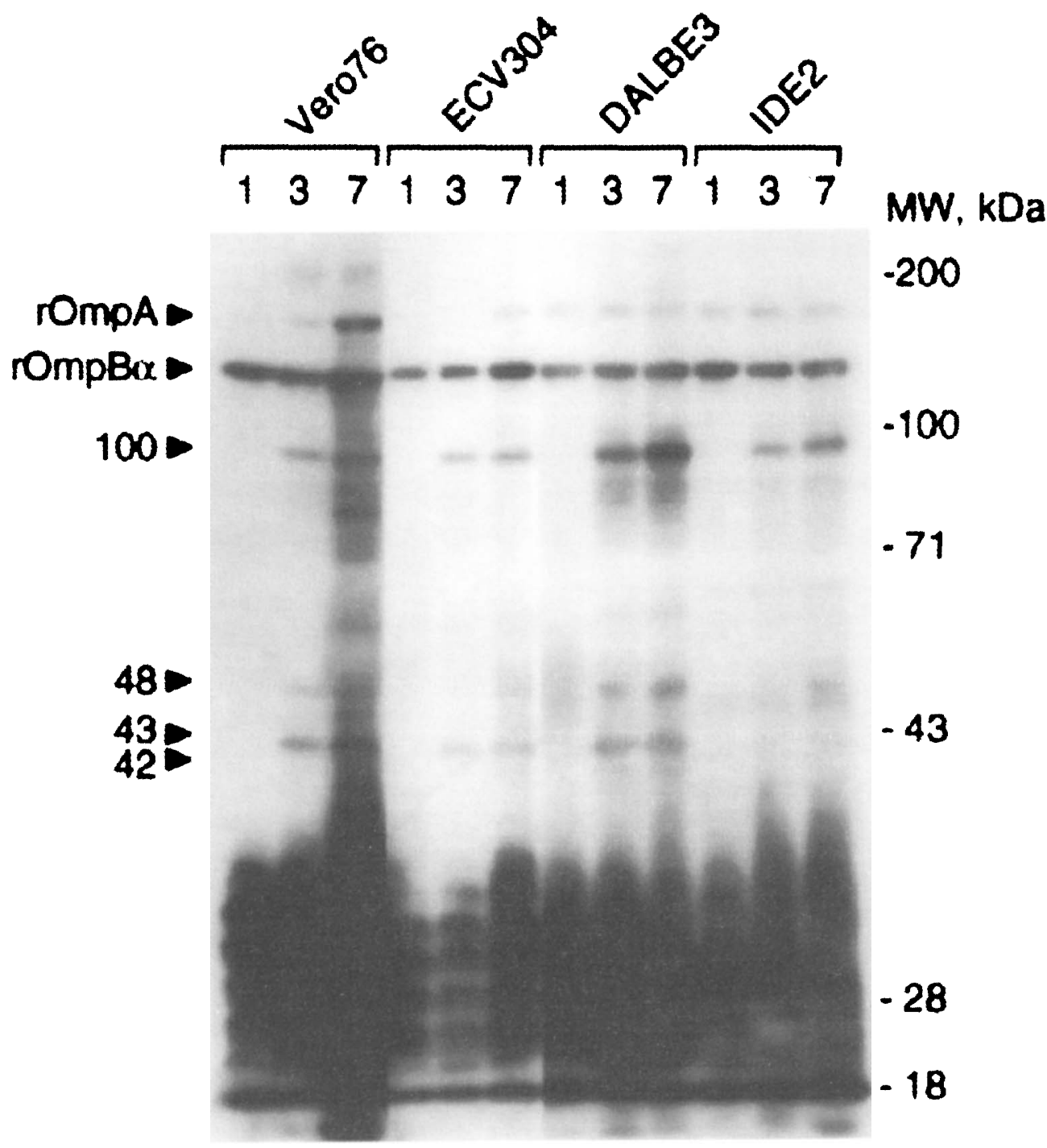

Fig. 3. $R$. rickettsii antigens during infection time course. Autoradiogram of immunoblotted Vero76, ECV304, DALBE3 and IDE2 cell lysates 1, 3 and 7 days p.i. All cells were infected at m.o.i. 0.01. Equal volumes of total cell lysate per time course were separated by SDS-PAGE. Filled arrrowheads indicate mobilities of known (rOmpA, $\mathrm{rOmpB} \alpha$ ) and unknown antigens. MW, kDa: migration of mol. wt standards as indicated by arrows.

salivary gland cells to vascular endothelium of mammalian hosts. Resistance to rickettsia-induced cytopathy in cell culture has also been observed in cultures of meadow vole (Microtus pennsylvanicus) tunica vaginalis cells. The mechanism of resistance in this cell type is also unknown. This vole species is suspected of acting as a mammalian reservoir for spotted fever [29].

$R$. rickettsii antigens with molecular masses of $42-$ $49 \mathrm{kDa}$ have been noted in other studies by immunoprecipitation of radioiodinated or intrinsically labelled proteins $[5,6,8,9]$. In these studies, antigens that probably represent $\mathrm{rOmpA}$ and $\operatorname{rOmpB} \alpha$ were the major reactive proteins. The tick cell infection model allowed the examination of temperature as a determinant of specific rickettsial protein expression. DALBE3 cells inoculated with rickettsiae and maintained at $28^{\circ} \mathrm{C}$ showed relatively little expression of a group of protein antigens compared to rOmpA and
rOmpB $\alpha$ (Fig. 3). An increase in temperature to $34^{\circ} \mathrm{C}$ for 5 days was sufficient to induce expression of 42-; $43-; 48-; 75-$ and $100-\mathrm{kDa}$ proteins. Development of monospecific immune reagents will be necessary to determine the subcellular localisation of these rickettsial proteins by microscopy and cell fractionation.

The immune sera used in the present study were raised against fixed rickettsial antigens expressed at $34^{\circ} \mathrm{C}$. Immune sera from infected human patients or animals, as used in the reports on rickettsial antigens noted above, were likewise directed against rickettsial antigens expressed at elevated temperatures. These sera would not be expected to detect hypothetical rickettsial antigens specifically induced in the 20 $28^{\circ} \mathrm{C}$ temperature range typical of the tick host. Additional studies will be required to determine if a subset of rickettsial proteins is specifically expressed during incubation in the arthropod host at reduced temperature. 
$\begin{array}{llll}\text { Ctri } & \operatorname{Rr} & \text { Ctrl } & \mathrm{Rr} \\ 28^{\circ} & 28^{\circ} & 34^{\circ} & 34^{\circ}\end{array}$

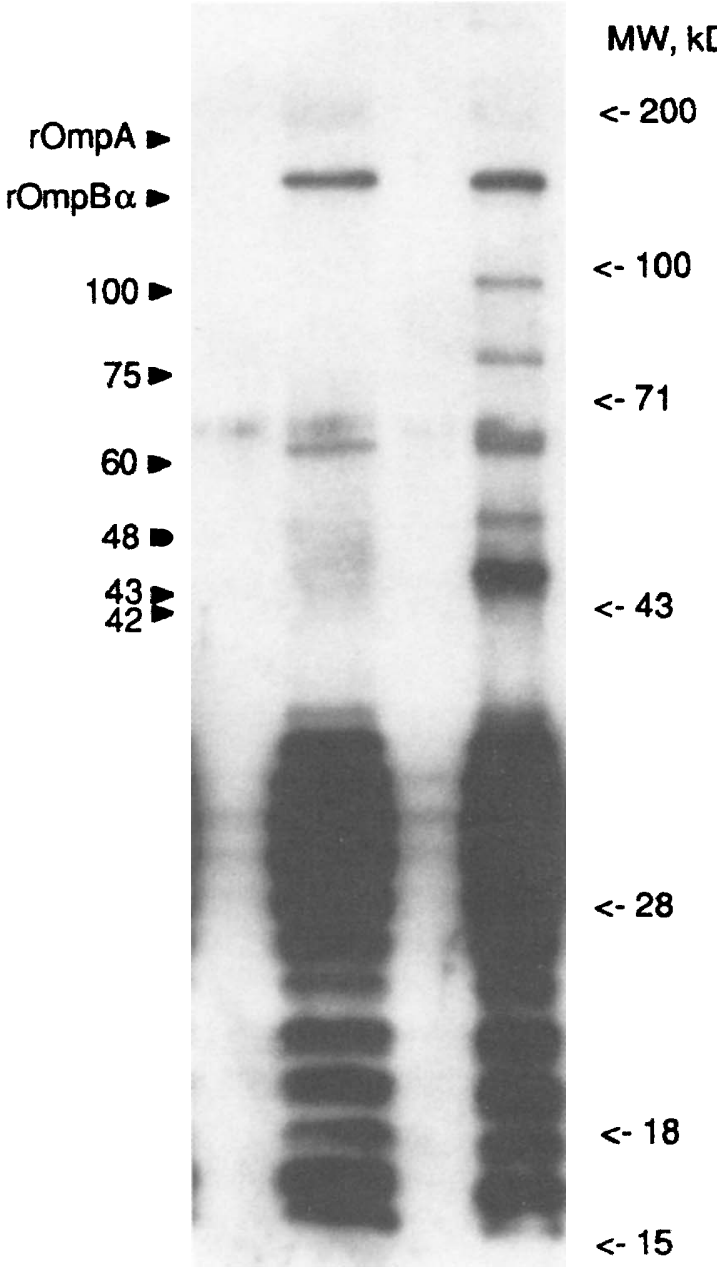

Fig. 4. Comparison of rickettsial antigen expression in infected tick cells at $28^{\circ} \mathrm{C}$ and $34^{\circ} \mathrm{C}$. DALBE3 tick cells were infected at m.o.i. 0.04 , incubated for $24 \mathrm{~h}$ at $34^{\circ} \mathrm{C}$, shifted to $28^{\circ} \mathrm{C}$ for 5 days and then either shifted to $34^{\circ} \mathrm{C}$ or maintained at $28^{\circ} \mathrm{C}$ for 5 additional days. At 10 days p.i., cells were sonicated and rickettsiae were partially purified by centrifugation through renografin $30 \%$. Solubilised pellets from infected $(\mathrm{Rr})$ or uninfected (Ctrl) cells were separated by SDS-PAGE and immunoblotted as in Fig. 3. Detection was by autoradiography. Mobilities of antigens and mol. wt markers are as described in Fig. 3.

Tick cell lines can provide a useful culture system to model nutrient and temperature effects on $R$. rickettsii protein expression and pathogenicity. In $R$. rickettsiiinfected $D$. andersoni ticks, rickettsiae are found in most cell types of the vector. In control ticks of this species, avirulent rickettsia-like organisms are found primarily in the reproductive organs [30]. Infectivity of spotted fever rickettsiae in the arthropod host may depend on a phenomenon termed 'reactivation'. Ticks infected with $R$. rickettsii and kept cold for several months to simulate overwintering did not cause overt disease when homogenised and injected into guineapigs. If such ticks ingested a blood meal or were kept at $37^{\circ} \mathrm{C}$ for $72 \mathrm{~h}$ before injection, guinea-pigs suffered typical spotted fever symptoms. This reactivation of rickettsiae was postulated to be linked to the metabolic state of the arthropod host [13,14], and may simply result from an increase in rickettsial infectious titre. A study of partially engorged, infected ticks showed a $10^{2}$-fold increase in haemolymph PFU compared to unfed, infected ticks [31]. However, in unfed $D$. andersoni ticks the $R$. rickettsii microcapsular layer was reported to dissociate from the rickettsial surface, and tick feeding or incubation at $37^{\circ} \mathrm{C}$ resulted in restoration of typical morphology [32]. This report is the first indication that induction of specific rickettsial proteins may be a component of the reactivation process. Tick cell cultures chronically infected with $R$. rickettsii will allow detailed examination of correlations between ultrastructure, induction of specific proteins and infectivity of spotted fever group rickettsiae.

We gratefully acknowledge the technical assistance of R. Mann and $M$. Peacock in providing rickettsial inocula, and the expertise of $B$. Evans and G. Hettrick in preparing the figures. We also acknowledge the helpful comments of T. Schwan and D. Rockey in reviewing the manuscript.

\section{References}

1. Burgdorfer W. Investigation of "transovarial transmission" of Rickettsia rickettsii in the wood tick, Dermacentor andersoni. Exp Parasitol 1963; 14: 152-159.

2. Burgdorfer W, Brinton LP. Mechanisms of transovarial infection of spotted fever Rickettsiae in ticks. Ann NY Acad Sci 1975; 266: $61-77$

3. Cox HR. Cultivation of Rickettsiae of the rocky mountain spotted fever, typhus and Q fever groups in the embryonic tissues of developing chicks. Science 1941; 94: 399-403.

4. Johnson JW, Pedersen CE. Plaque formation by strains of spotted fever rickettsiae in monolayer cultures of various cell types. J Clin Microbiol 1978; 7: 389-391.

5. Anacker RL, Philip RN, Williams JC, List RH, Mann RE. Biochemical and immunochemical analysis of Rickettsio rickettsii strains of various degrees of virulence. Infect Immun 1984; 44: 559-564.

6. Anacker RL, List RH, Mann RE, Hayes SF, Thomas LA Characterization of monoclonal antibodies protecting mice against Rickettsiae rickettsii. J Infect Dis 1985; 151: $1052-1060$.

7. Anderson BE, Regnery RL, Carlone GM et al. Sequence analysis of the 17-kilodalton-antigen gene from Rickettsia rickettsii. J Bacteriol 1987; 169: 2385-2390.

8. Feng HM, Kirkman C, Walker DH. Radioimmunoprecipitation of [35S]methionine-radiolabeled proteins of Rickettsia conorii and Rickettsia rickettsii. J Infect Dis 1986; 154: 717-721.

9. Williams JC, Walker DH, Peacock MG, Stewart ST. Humoral immune response to Rocky Mountain spotted fever in experimentally infected guinea pigs: immunoprecipitation of lactoperoxidase $125 \mathrm{I}$-labeled proteins and detection of soluble antigens of Rickettsia rickettsii. Infect Immun 1986; 52 $120-127$.

10. Miller JF, Mekalanos JJ, Falkow S. Coordinate regulation and sensory transduction in the control of bacterial virulence Science 1989; 243: 916-922.

11. Mekalanos JJ. Environmental signals controlling expression of virulence determinants in bacteria. $J$ Bacteriol 1992; 174: $1-7$.

12. Schwan TG, Piesman J, Golde WT, Dolan MC, Rosa PA Induction of an outer surface protein on Borrelia burgdorferi during tick feeding. Proc Natl Acad Sci USA 1995; 92: 2909 2913.

13. Spencer RR, Parker RR. Rocky mountain spotted fever: infectivity of fasting and recently fed ticks. Public Health Rep 1923; 38: 333-339.

14. Spencer RR, Parker RR. Rocky Mountain spotted fever: 
experimental studies on tick virus. Public Health Rep 1924; 39: $3027-3040$.

15. Munderloh UG, Liu Y, Wang M, Chen C, Kurtti TJ. Establishment, maintenance and description of cell lines from the tick Ixodes scapularis. J Parasitol 1994; 80: 533-543.

16. Munderloh UG, Kurtti TJ. Formulation of medium for tick cell culture. Exp Appl Acarol 1989; 7: 219-229.

17. Cory J, Yunker CE, Ormsbee RA, Peacock N, Meibos H, Tallent G. Plaque assay of rickettsiae in a mammalian cell line. Appl Microbiol 1974; 27: 1157-1161.

18. Laemmli UK. Cleavage of structual proteins during the assembly of the head of bacteriophage T4. Nature 1970; 227: $680-685$.

19. Batteiger B, Newhall WJ, Jones RB. The use of Tween 20 as a blocking agent in the immunological detection of proteins transferred to nitrocellulose membranes. J Immunol Methods 1982; 55: 297-307.

20. Silverman DJ, Wisseman CL, Waddell AD, Jones M. External layers of Rickettsia prowazekii and Rickettsia rickettsii: occurrence of a slime layer. Infect Immun 1978; 22: 233-246.

21. Hackstadt T, Messer R, Cieplak W, Peacock MG. Evidence for proteolytic cleavage of the 120-kilodalton outer membrane protein of rickettsiae: identification of an avirulent mutant deficient in processing. Infect Immun 1992; 60: 159-165.

22. Oaks SC, Osterman JV. The influence of temperature and $\mathrm{pH}$ on the growth of Rickettsia conorii in irradiated mammalian cells. Acta Virol 1979; 23: 67-72.

23. Walker DH, Firth WT, Edgell CJ. Human endothelial cell culture plaques induced by Rickettsia rickettsii. Infect Immun
1982; 37: 301-306.

24. Silverman DJ. Rickettsia rickettsii-induced cellular injury of human vascular endothelium in vitro. Infect Immun 1984; 44: 545-553.

25. Silverman DJ, Bond SR. Infection of human vascular endothelial cells by Rickettsia rickettsii. J Infect Dis 1984; 149: 201-206.

26. Rehacek J, Brezina R, Majerska M. Multiplication of rickettsiae in tick cells in vitro. Acta Virol 1968; 12: 41-43.

27. Yunker CE, Cory J, Meibos H. Tick tissue and cell culture: applications to research in medical and veterinary acarology and vector-borne disease. Acarology VI 1984; 2: 1082-1088.

28. Heinzen RA, Hayes SF, Peacock MG, Hackstadt T. Directional actin polymerization associated with spotted fever group Rickettsia infection of Vero cells. Infect Immun 1993; 61: 1926-1935.

29. Todd WJ, Burgdorfer W, Mavros AJ. Establishement of cell cultures persistently infected with spotted fever group rickettsiae. Can J Microbiol 1982; 28: 1412-1416.

30. Parker RR, Spencer RR. Rocky Mountain spotted fever: a study on the relationship between the presence of rickettsialike organisms in tick smears and the infectiveness of the same ticks. Public Health Rep 1926; 41: 461-469.

31. Wike DA, Burgdorfer W. Plaque formation in tissue cultures by Rickettsia rickettsii isolated directly from whole blood and tick hemolymph. Infect Immun 1972; 6: 736-738.

32. Hayes SF, Burgdorfer W. Reactivtion of Rickettsia rickettsii in Dermacentor andersoni ticks: an ultrastructural analysis. Infect Immun 1982; 37: 779-785. 